\title{
Novel Pyridoxamines for Enantioselective Biomimetic Transamination
}

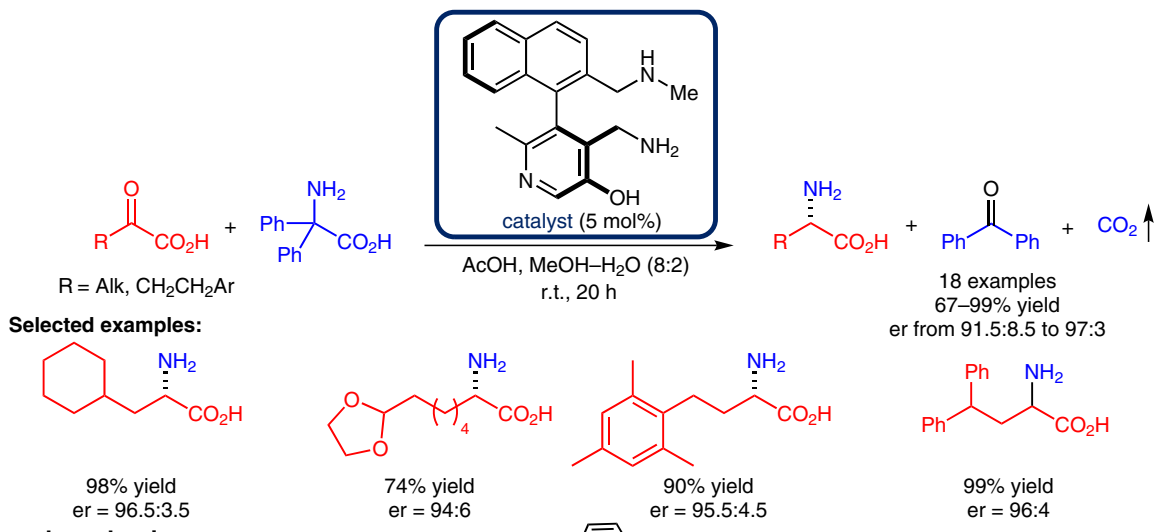

Proposed mechanism



Significance: Zhao and co-workers report a novel pyridoxamine catalyst bearing a lateral amine chain. Using this catalyst, they successfully mimicked the transamination activity of transaminases in converting $\alpha$-keto acids into the corresponding amino acids with commercially available diphenylglycine as the co-substrate; the reaction gave good yields and showed excellent enantioselectivity.

SYNFACTS Contributors: Benjamin List, Oleg Grossmann

Synfacts 2016, 12(11), $1195 \quad$ Published online: 18.10.2016

Dol: 10.1055/s-0036-1589304; Reg-No.: B07416SF
Comment: Transamination of $\alpha$-keto acids is a significant process for generating various amino acids in biological systems; consequently, great efforts have been made since the 1970s to achieve pyridoxamine-based biomimetic asymmetric transamination. In this work, enantioselectivities in excess of 90:10 were achieved under mild conditions for the first time. 